\title{
PRESENCIA DE ROSALÍA EN LA POESIA GALLEGA CONTEMPORÁNEA
}

Arcadio López-Casanova

Universitat de València

doi:10.17075/rcsxxi.2014.048

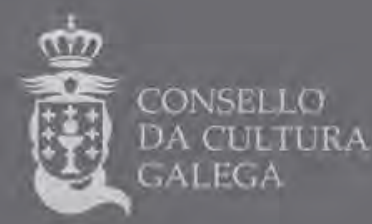



Muy en primer término, quiero agradecer a Ángel Basanta sus tan generosas palabras de presentación — advertirán ustedes que son las palabras de un amigoy agradecerle, también, su cordial invitación a participar en este ciclo rosaliano que, organizado por el Consello da Cultura Galega y acogido por el Instituto Cervantes, conmemora el ciento cincuenta aniversario de Cantares gallegos, la obra emblemática del Rexurdimento literario.

Una invitación — he de decirlo- que acepté encantado, desde la emoción y la devoción, por todo lo que nuestra autora — Nai de Galicia, para decirlo en expresión pimenteliana - ha representado y representa para mí. Descubrí a Rosalía allá en los años — - ya tan lejanos! — de mi adolescencia luguesa, cuando, cursando tercero de bachillerato, en las páginas de la Historia de la Literatura de Díaz-Plaja se me reveló la dolorida imagen y la dolorida palabra de la cantora del Sar. Desde entonces, aquella figura y aquella palabra han sido compañía y guía, han estado conmigo en todo tiempo y circunstancia a lo largo de los años, y a ellas he intentado dedicar mi más sentida palabra creadora y mi más escrutadora mirada crítica.

Yendo hacia el tema que hoy nos ocupa, vamos a intentar una visión — cierto que necesariamente general y en esquema - de la presencia de Rosalía en la lírica gallega contemporánea. Una visión siguiendo dos líneas o perspectivas que - entiendo - se entrecruzan y complementan. Por una parte, atendiendo a determinadas representaciones líricas que de nuestra autora nos han legado a lo largo del tiempo algunos destacados poetas, para, sobre ellas, ver cómo se ha ido interpretando la figura rosaliana. Por otra parte, fijando los períodos de articulación de la contemporaneidad lírica, viendo cuáles son, en cada tiempo, las poéticas canónicas y dominantes y sus ramas de desarrollo, para así, a través de ese tejido histórico-literario, ver y precisar la naturaleza y sentido de la huella que la gran poeta ha dejado. 


\section{UNA ETAPA DE TRANSICIÓN}

Pues bien, y siguiendo los puntos señalados, una primera etapa se establece en la poesía gallega contemporánea entre 1890 y 1916, es decir, entre la fecha que cierra el Rexurdimento, la restauración cultural del siglo xix y la que, en el otro extremo, apunta — como más adelante veremos— a los signos de la modernidad.

Es un cuarto de siglo que se caracteriza, en el ámbito de la lírica, por responder a una epigonía, o lo que es lo mismo, por dar continuidad — claro que con valores y matices de singularidad-a la poética canónica del Rexurdimento. Se trata de una poética que podíamos considerar de signo socio-antropológico y que se articula en tres eje de sentido: la lengua, la Tierra y el pueblo. La lengua, tesoro que se recoge de la boca del pueblo, de la Galicia marinera y labradora, que la conservó a lo largo de los siglos oscuros, y ahora se ensalza con sentimiento y se quiere dignificar elevándola al cultivo literario: "Cantarte hei, Galicia, / na lengua gallega, / consolo dos males / alivio das penas. / Mimosa, soave, / sentida, queixosa, / encanta si ríe, / conmove si chora», dirá Rosalía.

La Tierra, luego, —a Terra-Nai- como imagen idílica, «centro» de arraigado sosiego, vista en sus paisajes, en sus ritos y costumbres, en sus devociones, en sus tipos, en el vivificador poso de la tradición. Y el pueblo, en fin, que aparece dominado por la injusticia, explotado por los poderosos, como abatido — siempre víctima- por las oscuras fuerzas de la Historia, y al que solo queda la sumisión o la huída (o - acaso- soñar la rebeldía).

De esta poética reseñada (y, más en concreto, sobre sus dos claves primeras, lengua y Tierra) va a nacer y desarrollarse una rama lírica la del enxebrismoenormemente fecunda que - ahí la relevancia - tiene su modelo en los Cantares gallegos rosalianos, el emblemático poemario con el que nuestra poeta levanta una estilización idílica de Galicia dedicada — como advierte en el prólogo- «a los de fuera», mostrando en preciosos cuadros o estampas líricos los valores, los encantos, la belleza de su tierra.

Pues bien, esa rama lírica del enxebrismo - y, consecuentemente, el modelo de los Cantares - va a tener una decisiva presencia en esa etapa primera de la contemporaneidad, en ese primer período de signo epigónico, y va a dar sentido a parte fundamental de los libros iniciales de Noriega y Cabanillas, los dos grandes líricos que afloran en esos momentos. 
En Noriega sigue presente — como en los poetas del Rexurdimento—-la defensa sentimental del idioma, la exaltación idealizadora del gallego, y el dolorido temor a su pérdida:

\author{
¿Y ha desparecer conmigo, \\ vai expirar nos meus labios \\ o gallego, esta faliña, \\ «Cristo das lenguas», que exalto? \\ [...] \\ Y-a Fala, ¡a floriña humilde \\ d'os ermos!, o Idioma patrio \\ en que as fonteliñas rezan \\ e garulan os paxaros, \\ aínda máis que á rosa d'ouro \\ ¡que bendice o Padre Santo!, \\ ¡máis aínda, Pai d'o ceyo, \\ o veneran meus paisanos!
}

En Montañesas —su primer libro, 1904-, el escenario y la protagonización corresponden, según el título indica, al espacio lírico de la montaña y a los campesinos brańegos, de los que nos da sus trabajos, su quehacer diario, sus alegrías y sufrimientos. Como hacía Rosalía — pero aquí con la concreción escénica y actorial apuntada - el poemario representa un conjunto homogéneo de cuadros o estampas de gran vigor descriptivo, ricos de matices y coloridos, en los que dibuja líricamente toda una intrahistoria social cercana a sus ojos y sentimiento: apuntes de fiestas populares, de costumbres tradicionales, de tipos y formas de vida labriegos, o apuntes del tan amado paisaje de la montaña (que luego será central en $D^{\prime}$ o ermo).

En los primeros libros de Cabanillas — No desterro (1913) y Vento mareiro (1915) — también se hace patente — como dijimos - la huella del enxebrismo, que se combina con la temática civil y social y, también, con la de más honda vibración íntima, de manera que el Poeta da raza, según apuntó Carballo Calero, "pola gracia das súas dotes líricas, vibra ao compás das almas dos grandes precursores, e sendo moito máis que iso — sendo Cabanillas-é, ao mesmo tempo e 
todo dunha vez, o mellor continuador de Curros, de Rosalía, que rexistra a nosa historia literaria».

Poemas — por citar algún ejemplo de No desterro - como "Cencia do adro», "O vello que foi ladrón», «A campana choca», o «Na casa vella» $\mathrm{o}$ «Dous raposos", de Vento mareiro, son muestras preciosas que acreditan el acierto y la altura poética del cambadés al trazar sus estampas llenas de vida, de colorido, de gracia, cuando no de contenido dramatismo. Y algo más, y muy importante: su buena formación literaria hace que en él, en su poesía, el enxebrismo rezume gusto clásico, esté tamizado por modelos y moldes clásicos, de modo que sus poemas limitan el pintoresquismo más ruralista y se enriquecen con toda una tópica clásica —el contemptus mundi, el elogio de la vida retirada, el locus idílico, etc. tratada con intensidad y originalidad. Recordemos, como muestra significativa, unos versos de «Sono dourado», que abre Vento mareiro:

\footnotetext{
¡Ou meu sono labrego! Unha casiña preto do río, ó abrigo dos pinales, con piorno e alboios nos currales e palleiros na eira e na curtińa. Ó pé da casa un muíńo cantareiro ó son de lira de ágoa que enche o caño, baixo o maino agarimo dun castańo e os amorosos brazos dun cruceiro. $[\ldots]$
}

\section{SIGNOS DE MODERNIDAD}

Entre 1916 y 1936 puede delimitarse otra etapa o período, ahora caracterizado, frente a la epigonía anterior, por la irradiación - ya - de los signos de la modernidad, por el diseño de la Galicia ideal que van configurando los maestros de Nós - Castelao, Otero Pedrayo, Risco-y, en el ámbito de la lírica, que es lo que nos interesa, por el surgimiento y la manifestación de la generación de la vanguardia o del 22 - la de Manuel Antonio, Amado Carballo, Pimentel, Bouza-Brey, Acuña, Casas—, a los que hay que ańadir los poetas del Grupo de la 
República (Cunqueiro, Iglesia Alvariño, Carballo Calero), generación marcada para decirlo en términos orteguianos - por un signo polémico y de ruptura.

Esa razón rupturista está bien explícita en el manifiesto «Máis alá» (1922), firmado por Manuel Antonio y Álvaro Cebreiro, y en un curioso texto del rianxeiro — «Prólogo dun libro que ninguén escribeu»— que tiene verdadero valor de poética (personal y generacional), y en el que dice:

O autor deste libro, a diferenza dos poetas da súa terra, tan homildosos devotos da Santa, do bardo e do Rebelde, non por asomellarse a ninguén, e moito menos ó consabido trío, fixo da súa independenza un sagro fanatismo [...]. Botouse o traballo de facer un molde propio para o seu lirismo, sin reparar no celeiro de moldes feitos que deixaron os inesquecentes Precursores.

Esos moldes nuevos de los que nos habla el autor de De catro a catro son, ni más ni menos, que los que corresponden a la llamada concepción asociativa de la poesía, esto es, la poética epocal determinante de la lírica moderna que se desarrolla en Europa desde 1867 - la muerte de Baudelaire- a los ańos 30 y que los poetas citados aportan, con radical acento renovador, a la poesía gallega en esta etapa. Una poética — conviene tenerlo presente- con tres principales fundamentos, tres claves:

a. Primero, la presencia de un sujeto moderno (opuesto al del intimismo sentimental romántico), ya no unitario y monológico sino complejo, proteico y polifónico, un yo que ahonda en el laberinto interior, en las abismales galerías del alma, y que — para decirlo con Unamuno— allá en las "pantallas del alma propia» se proyecta disperso, discontinuo, escindido.

b. Segundo, el dominio de las máscaras del yo, de actitudes encubridoras, bien por pudor afectivo (que controla la eclosión sentimental) o bien por distancia síquica que posibilita la introspección, el descenso al reino interior, a esas oscuras regiones de lo «incognoscible del yo».

c. Tercero, el triunfo de la fantasía dictadora, esto es, de una imagen nueva, de fundamento subjetivo, de índole poderosamente irracionalista, simbólica. En este punto, reseñados estos principios que rigen la escritura de la generación de la vanguardia, me interesaría llamar la atención sobre una cuestión que 
me parece decisiva, y que quizás la crítica no ha valorado con suficiencia. Se trata de lo siguiente.

La Rosalía de Follas novas, su poemario de 1880 (con poemas escritos en los primeros ańos 70), está anticipando, está respondiendo a estos fundamentos de la modernidad poética, y no de manera suelta y esporádica, sino desde un trabado sistema de mundo representado y de estilo, de modo que ese libro suyo supone un verdadero — y solitario- hito anticipador en la lírica gallega y — por supuesto-en la lírica peninsular.

Ahora bien: si esto es así, si es cierto ese signo anticipador de nuestra poeta, y los creadores del grupo vanguardista son los que, a lo largo de los años 20 y primeros 30, establecen con madurez la poética de la concepción asociativa, ¿por qué - tendríamos que preguntarnos ahora — la presencia o huella rosaliana se diluye, se difumina en esta etapa? ¿Ante que llamativa paradoja estamos?

Creo que la respuesta ha de ser doble, porque hay dos tipos de razones. Por una parte, no se da una «lectura» correcta, en claves de modernidad, de la obra rosaliana, de su palabra más anticipadora, como se pudo advertir en la cita de Manuel Antonio, quien, por cierto, en el manifiesto "Máis alá», en el apartado de "Os devanceiros», alude — cito——á socorrida e ridícula "pose” do falso romanticismo, enfermedade de moda naquil tempo, que chegou a deslucir algunhas das páxinas grandes e persoais de Rosalía».

Por otra parte, el espíritu generacional, la actitud iconoclasta, la actividad y la experimentación vanguardista (tan decisiva en Manuel Antonio, en Acuña o Cunqueiro) y, luego,. las ramas líricas definidoras del grupo —el impresionismo sentimental y eglógico, el esteticismo metapoético y culturalista, el esencialismo, la tendencia simbolizante — hemos de admitir que poco —o nada— son concordes con el decir lírico rosaliano.

Que la huella de nuestra poeta se diluya o desvanezca no va a impedir, sin embargo, que tengamos muestras admirables de esa presencia, como es el caso de dos ejemplos que vamos a considerar. Los dos, que se dan en los límites de esa etapa, en los años 1935-1936, y los dos, además, coincidentes en presentarnos una intensa y dramática visión mítico-simbólica de Galicia, con Rosalía como figuración esencial.

El ejemplo de 1935 corresponde a los Seis poemas galegos de Lorca, un conjunto que en general — hay que decirlo — la crítica lorquiana y la crítica gallega 
apenas han valorado, considerando, a menudo, que se trataba de un «juego» del genial granadino. Y nada hay en ellos de juego, pues, ciertamente, estamos ante un conjunto de acabado diseńo y de un doble valor. De un lado, significa una aportación relevante a la nueva «manera espiritualista» propia de su último ciclo lírico; de otro lado, es una aportación de decisiva importancia a la lírica gallega, justamente — según hemos seńalado - en una etapa crucial de renovación, de apertura a la modernidad.

Y es que Lorca acierta, además, a calar en el ser profundo de Galicia, a ahondar en las entrańas misteriosas de su pueblo, y logra expresarlo con la más alta sensibilidad lírica en una representación transida de dramatismo y unos muy precisos formantes: el escenario emblemático de Compostela (que abre y cierra), dos protagonistas emparejados —el emigrante y el joven campesino del Sil— sujetos de la desposesión, víctimas de muerte suicidaría (por morriña/por amor), y dos figuras femeninas donadoras, positivas, también emparejadas en el diseño, la Virxe da Barca y Rosalía.

Atendamos a la "Canzón de cuna pra Rosalía de Castro morta», enmarcada —al estilo rosaliano- por un cantar de alba:

¡Érguete, miña amiga,

que xa cantan os galos do día!

¡Érguete, miña amada,

porque o vento muxe, coma una vaca!

Os arados van e vên

dende Santiago a Belén.

Dende Belén a Santiago

un anxo ven en un barco.

Un barco de prata fina

que trai a door de Galicia.

Galicia deitada e queda

transida de tristes herbas.

Herbas que cobren téu leito

e a negra fonte dos teus cabelos.

Cabelos que van ao mar

onde as nubens teñen seu nidio pombal. 
¡Érguete, miña amiga,

que xa cantan os galos do día!

¡Érguete, miña amada,

porque o vento muxe, coma una vaca!

Se advertirá la complejidad —y originalidad — de la urdimbre imaginativa, con su base en la relación de noche-muerte como sueño y alba-despertar que es renacer, asociado a un pueblo — «Galicia deitada e queda»— sumergido en la vivencia de la radical orfandad y conmovido por un inmenso dolor de pérdida.

A eso se añaden, luego, los dos espacios - Santiago, el espacio sepulcral / Belén, el foco del nacer, de la redención- entre los que se establece una ruta, un viaje. En un primer viaje de esa ruta — repetido ir y venir- los «arados» representarían el esfuerzo de siembra y fecundación, de buscar con sacrificio y dolor la redención vivificadora. En un segundo viaje — nocturno, por el mar, «dende Belén a Santiago»— se da, ciertamente, el anuncio, la señal («un anxo ven en un barco» [...] «un barco de prata fina») que ha de entenderse como signo sagrado o urna dotada (guarda el dolor de Galicia) de poder redentor. A la luz de estas bases, cobra después claro sentido, en la parte final del poema, toda una cadena de imágenes (simbólicas) — «fonte», «mar», «nubens», «pombal»— que arrancan del lecho — tumba — de Rosalía, todas ellas convergentes en el común significado de renacimiento, de poderes vivificadores, de sublimadora purificación.

En 1936, ya cerrando esta etapa, vamos a encontrar el segundo ejemplo que anunciábamos, y que se abre con la publicación en la revista luguesa Resol del poema que Luis Pimentel — sin duda el más hondamente rosaliano de su generación - dedica a la cantora del Sar. Ahora bien, y desde esa fecha, habrá que esperar - primero- a 1950, a la publicación de su breve poemario Triscos, y después - al ya póstumo Sombra do aire na herba (1959), para que el admirable conjunto pimenteliano, y su no menos compleja representación mítico-simbólica de Galicia (con Rosalía como figura central), alcance acabado diseño. Una representación que se levanta sobre tres constituyentes, cada uno con su concreto reparto y valor: una localización, Compostela; una actorialización, el poeta/profeta; una figuración, Rosalía.

Entrando muy por encima en el tejido de esa representación, Compostela escenario emblemático— aparece como «montaña sonora de tallada piedra», esto 
es, imagen que participa del «centro» y la altura, espacio de reencuentro de tierra y cielo, ámbito propicio a las revelaciones de lo sagrado. Se entenderá, entonces, que sea en Compostela donde el poeta/profeta quiera «queimar os farrapos», esto es, abandonar la vieja vida para acercarse a un estado vivencial de orden superior. Por eso, cuando afirma "xa queimei os meus farrapos / en Compostela», el poeta surge transformado, portador de dones especiales y a la espera de la revelación iluminadora.

En ese conjunto, toda la impresionante figuración rosaliana («boneca de sombras»), sus rasgos caracterizadores («boca torta», "pómulos marelos deformes pola dor», «seios esprimidos»), su localización («errante polos fondos camiños», "na solaina da súa casa deserta») y, asimismo, los signos escénicos que siempre la acompañan («día que esmorece», «noite», «campás de ferro», "ceo brando, / mouro e desfeito», «chuvia e brétema») dan una sobrecogedora dimensión fantasmal y fúnebre.

Ahora bien, ¿qué se quiere expresar con tan compleja figuración, tan central y decisiva en el conjunto de la visión, de la representación? Entiendo que todo viene a ser signo convergente de una misma realidad espiritual, y que convierte a Rosalía en figuración (simbólica) de la vivencia de la radical orfandad, del radical desamparo, del vacío último que se abre al abismo de la angustia. Rosalía como símbolo de un pueblo sumido en la «des-gracia», a la espera de que el poeta/profeta escogido logre sostener «o peso do clamor» y sea capaz de alzar el camino de la luz, de la vida nueva, de la redención sublimadora.

\section{DE LA POSGUERRA A LAS ÚLTIMAS POÉTICAS}

Tras la guerra civil de 1936, el esforzado proceso de restauración cultural en el período de posguerra se abre en 1947 con la publicación del poemario Cómaros verdes, de Iglesia Alvarińo, celebrado en aquel entonces por la crítica como canónico de la más genuina poesía gallega. Es un libro muy valioso y hermoso que responde a un renovado enxebrismo, vivificado y dignificado por la mejor tradición bucólica clásica, en el que nuestro poeta levanta la gran égloga de su tierra nativa, de sus horizontes familiares, los campos de Seivane, Aldear y Lamanide, 
los agros de A Pastoriza, allá donde el Miño se va haciendo pastor de ríos. Ahora bien, ese enxebrismo no va a tener una continuidad significativa.

La renovación lírica que aporta el período (o, al menos, ramas y tramos muy representativos) creo que en gran parte se debe — si no me equivoco- a la presencia y a la huella de Rosalía. Para ser más preciso, su punto de partida e inflexión va a estar en 1952, con la publicación del volumen colectivo de los Sete ensaios dedicados a nuestra poeta. Del citado volumen nos interesan especialmente dos estudios, el de Celestino Fernández de la Vega y el de Ramón Piñeiro, porque en ellos vamos a encontrar renovadas aproximaciones a su lírica, una «lectura» moderna de Follas novas (la que no advirtieron — salvo Pimentel— los de la generación de la vanguardia), sobre todo de las partes primeras del poemario (las de la palabra ensimismada y la extremosidad vivencial). Más todavía y muy relevante: esa lectura renovadora que aportan los dos ensayistas propicia una fecunda relación de su mundo y escritura poéticos con claves de la poética epocal que ahora se hace canónica, y que tiene su foco cosmovisionario motivador en la imagen del "hombre-situado-en-el-mundo», y, desde ahí, el tema de la vida como proyecto, de la existencia en su devenir temporal abierta a la finitud y a los signos de la ultimidad.

La categorización que Fernández de la Vega presenta de Rosalía como poeta en tiempo menesteroso, como voz que canta desde la noche del mundo, voz que interpreta y asume las seńales de la des-gracia, de la ausencia de los dioses, podemos decir que conecta e incide en una línea o vertiente de la rama existencial que cristaliza, en nuestra lírica, en lo que Méndez Ferrín llamó con acierto Escola da tebra, y que se desarrolla a lo largo de una década, entre 1952 y 1961.

Es una línea o vertiente realmente rica, fecunda, que, curiosamente, encuentra su mejor representación en dos libros —uno de apertura, otro de cierre apenas atendidos en su momento por la crítica. En la apertura que señalábamos -1952 — está Fabulario novo de Cuńa Novás, poemario muy unitario atemperado por una oscura tonalidad de sentimiento, por un temple anímico de intima tenebrosidad, en el que tiene voz un sujeto visionario del desasosiego, y en el que parecen resonar aquellos versos rosalianos de un yo lírico que se abisma, se desdobla y se interroga: 
—¿Qué ves nese fondo escuro?

¿Qué ves que tembras e calas?

-Non vexo! Miro, cal mira

un cego a luz do sol crara.

E vou caer alí en donde

nunca o que cai se levanta.

Títulos representativos y significativos de Fabulario novo — «Día de difuntos», «Trebón perpetuo», «Desterro insone», «Adoescente morto»— creo que ya apuntan muy bien a esa vivencialidad de la negrura existencial, de la angustia que sobre todo se desborda y todo lo invade. Dirá así, con viva orquestación, en un fragmento:

Caen e roldan as follas ao redor da i-auga

como si fora o seu dicir: chorade.

Tanguen as campás silenzo sin amparo

como si fora o seu tanguer: chorade.

Chorade aos ancrados na soma e na morte,

aos núos sulagados na terra lividosa;

$[\ldots]$

El cierre de esta línea o vertiente, de esta Escola da tebra de tan rica incidencia rosaliana, se establece en 1961 con Lanza de soledá de Iglesia Alvariño. Aquel admirado poeta del renovado enxebrismo publica ahora una de las cumbres de la lírica gallega de todos los tiempos, que — como dejamos apuntado- pasó casi desapercibida.

El conjunto es un riguroso - y poderoso- cancionero de la desolación en el que el soneto - presente ya en Noriega y Cabanillas — alcanza toda plenitud y perfección. En los signos de protagonización, aparece un «él» que —como en ejemplos rosalianos («Estranxeira na súa patria») es, en gesto de modernidad, una máscara encubridora del «yo». Un «él» que da figuración a un sujeto —-muy del gusto también de nuestra autora- de la desposesión, modulado, a lo largo del dramático conjunto del cancionero, por una fatídica melodía de la lamentación: 


\footnotetext{
Alguén —e be-no oía — lle berraba.

Mais el estaba solo nun aberto;

a súa delor, ben viva, no ben certo

ollo da súa concencia. Non marraba.

En dura luz de laz muros alzaba

o triste ó seu redor. Naquel deserto,

zarrado sobre si, namáis, desperto,

vía que a noite diante del medraba.

[...]
}

Al prodigio de la forma y el ritmo, habría que añadir todo un trabado sistema imaginativo, toda una urdimbre simbólica —el dominio del régimen nocturno, «a sombra», «o mar», «o vento», «a rosa»...- y una cadena de palabras-tema — «laído»/«olvido», «delor»/«tormento», «coita»/«ansia», etc.—, con lo que ese «él»/sujeto de la desposesión acierta a expresar y comunicarnos su radical desvalimiento existencial.

Por su parte, la reflexión de Piñeiro sobre la saudade y su aplicación de la saudade a la lírica rosaliana en el estudio que dejamos citado puede decirse que abre otra original vertiente en la rama existencial y que, en este caso, amplía su desarrollo en el tiempo.

El más original y valioso ejemplo de esta línea lo aporta Novoneyra, que bien significativamente- cerraba Os eidos (1955) con un apartado que titulaba «Ondas de saudade» y en el que podíamos leer el «Laio de Novoneyra»:

\footnotetext{
Escurecen os penedos...

Baixa a sombra do ucedo

aniárseme no peito...

[...]

Ista dor! Ista dor! Ista

dor miña!

Berro caído nun couso...

A dor alúmame todo

e ollo a morte no fondo...
} 
Queda prefigurado ya ahí, y se figurativizará definiticamente en Os eidos-2 (1974), sobre todo en la parte Diario de enfermo, lo que sin duda es y llamaríamos mito personal del doliente saudoso, una figuración recurrente del yo novoneiriano, proyección simbólica del autor, que da protagonización y sentido a un conjunto sustancial (y muy original) de su obra.

En este caso, se trata de un sujeto lírico que, desde el ensimismamiento existencial («nada me chama / dentro nin fora») vive un proceso de íntima transformación, a la espera de nuevos signos reveladores. Un sujeto, además, que pierde la vibración del tiempo (que pasa vacío de sentido) y que también pierde el sentido de la mirada, esto es, del conocer y reconocer («Os ollos tein / unha ollada longa / sin ida nin volta»). Mirada vacía, sí, pero abierta a los signos que acaso puedan traer la revelación vivificadora.

En 1962, con la publicación de Longa noite de pedra, de Celso E. Ferreiro, se produce un giro significativo en la lírica gallega, pues de la rama existencial —de tan evidente huella rosaliana- se pasa a un realismo del mundo y de la gente, al canto de signo civil y social.

Lo importante, para nuestras consideraciones, radica en que el modelo es ahora Curros, o — más exactamente- la rama del patrianismo que arranca de él en el Rexurdimento, y que va a tener como enlace al Cabanillas de Da terra asoballada (1917). Rosalía, pues, queda ahora en un segundo plano, y diríamos más todavía: en ese segundo plano, el interés se va a desplazar — para utilizar términos de Alonso Montero- de su palabra solitaria (propia de las partes primeras de Follas novas) a la palabra solidaria (la que da sentido a «Da terra» $\mathrm{y}$ «As viudas dos vivos e as viudas dos mortos»).

Se trata — con evidencia- de la Rosalía que se identifica moralmente con su pueblo, con los desposeídos, con las víctimas que padecen la Historia. Es la Rosalía que, en gesto de modernidad, construye un monólogo escénico y en él da protagonización y voz — voz de lamento y denuncia — a una de esas viudas de vivos o muertos, dramático ejemplo de sujeto de la desposesión. Es lo que, sobre su modelo, hará Celso Emilio en su «Monólogo do vello traballador»:

\footnotetext{
Agora tomo o sol. Pero até agora

traballéi cincoenta anos sin sosego.

Comín o pan suando día a día
} 
nun labourar arreo.

Dinlle ó patrón a frol do meu esforzo

i a miña mocedade. Nada teño.

[...]

Entre 1976 y 1981, una serie de obras que hay que considerar emblemáticas - Con pólvora e magnolias, de Méndez Ferrín; Tempo de Compostela, de García-Bodaño; E direivos eu do mister das cobras, de Manuel Vilanova; Herba aqui ou acolá, de Cunqueiro - apuntan a signos de radical ruptura. Una ruptura que luego, en las décadas finales del siglo, va a desarrollar una vigorosa generación de los 80 —Álvarez Cáccamo, Fernán Vello, Seoane, Tosar, Valcárcel, Fonte, Raña, Rodríguez Barrio, Rodríguez Fer - y que, al menos en una primera etapa (de especial rebeldía), va a mostrar unos rasgos que caracterizaremos y resumiremos así:

i. Frente al poema como objeto ideológico (propio del realismo), su revalorización como objeto estético pleno y la consideración de la poesía como arte del lenguaje.

ii. Frente al prosaísmo y el desaliño estilístico, la preocupación por la riqueza imaginativa y el esmero compositivo.

iii. Frente a la búsqueda de la claridad y de la inmediatez comunicativa, la opacidad, la oscuridad, el hermetismo.

iv. Frente al limitado campo temático, un abanico de ramas o de líneas de sentido como el esteticismo metapoético y culturalista, el gusto por escenarios y rutas exóticos, el erotismo como subversión, el paisaje y la vida urbanos, etc.

v. Frente a la limitación de los modelos, apertura y contacto con la poesía portuguesa, inglesa o catalana, o —en el ámbito gallego- enlace sobre todo con el experimentalismo vanguardista (de Manuel Antonio o Cunqueiro).

La apretada caracterización que de los rasgos generacionales acabamos de hacer creo que nos evidencia, con suficiencia, que — como ya sucedía en los años 20 y 30 - es mínimo (por no decir nulo) el acorde de estos principios con la palabra lírica rosaliana. Dicho de otra manera: si en el realismo del mundo y la gente el modelo gallego estaba en el patrianismo de Curros (o, en todo caso, en la Rosalía de la palabra más solidaria), ahora, tras la radical ruptura, los modelos van a ser, muy principalmente, Manuel Antonio y Álvaro Cunqueiro, de marcado relieve esteticista. 
Ahora bien, tras esa primera etapa rupturista, y en el camino hacia su madurez poética, los miembros de esta generación, sin dejar sus fundamentos más esenciales y definidores, puede decirse que van girando hacia formas de intrahistoria personal, de memorialismo y conciencia histórica, hacia temáticas de revelación existencial, en las que vuelven a aflorar a la protagonización del poema determinadas tipologías del sujeto lírico — de la desposesión, de la privación, del extravío-, sin duda más, mucho más en consonancia con advertidos modelos rosalianos que ya mostraron su vigencia en el desarrollo de la rama existencial de los años 50. Obras recientes como Estúrdiga materia de González Tosar, Diccionario do estremecemento o Habitación do asombro de Fernán Vello, No ventre da cóbrega de Seoane o Calado testamento de Rodríguez Barrio son muestras espléndidas del nuevo signo lírico que en estos momentos, en estos tiempos de tanta menesterosidad espiritual y social, aporta su generación a una renovada y muy floreciente poesía gallega de esta hora. Una poesía sobre la que resuena, honda y misteriosa, la estremecida voz de la tan amada Nai de Galicia. 
